\title{
Linked photoswitches where both photochromes open and close.
}

Reginald H Mitchell* and Subhajit Bandyopadhyay.

Department of Chemistry, University of Victoria, P.O. Box 3065,

Victoria, British Columbia, Canada V8W 3 V6

regmitch@uvic.ca

SUPPORTING INFORMATION 


\section{Synthesis of Photochrome 5}

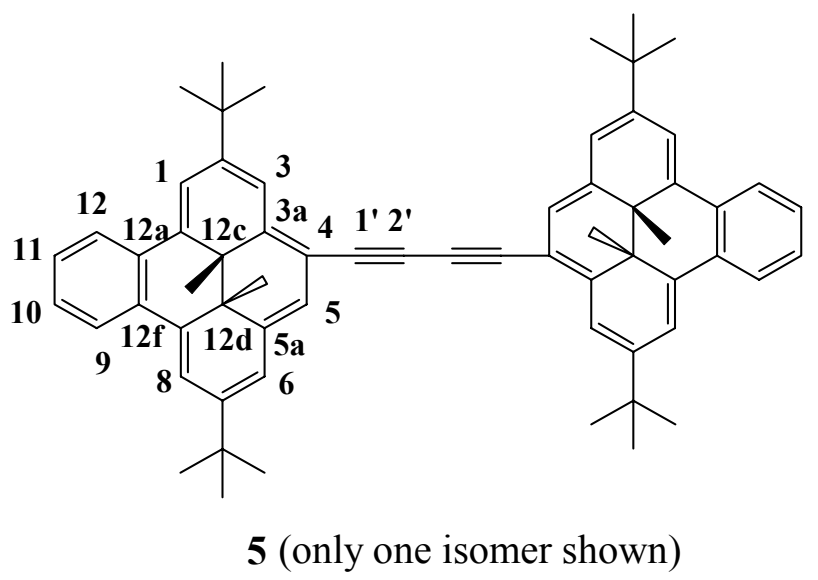

Dichloro-bis-(triphenylphosphine)palladium (II) (14.1 mg, $0.02 \mathrm{mmol}), \mathrm{CuI}$ ( $4 \mathrm{mg}, 0.02 \mathrm{mmol})$ and benzyl triethylammonium chloride $(4 \mathrm{mg}, 0.02 \mathrm{mmol}$ ) was added to a solution of the bromide $4^{1}$ (188mg, $\left.0.40 \mathrm{mmol}\right)$ and 2,7-dimethylocta-3,5-diyn-2,7-diol ${ }^{2}$ (34 mg, $\left.0.20 \mathrm{mmol}\right)$ in dioxane $(10 \mathrm{~mL})$. The mixture was purged with argon for $20 \mathrm{~min}$, and then aq. $\mathrm{NaOH}(5.5 \mathrm{M}, 4$ $\mathrm{mL}$ ) was added by syringe, and the reaction was heated under reflux for $2.5 \mathrm{~h}$. After cooling to $20^{\circ} \mathrm{C}$, excess of satd aq. $\mathrm{NH}_{4} \mathrm{Cl}$ was added, and stirring was continued for $30 \mathrm{~min}$. The reaction mixture was then extracted with ether $(3 \times 50 \mathrm{~mL})$, washed with water, dried over anhydrous sodium sulphate and evaporated to dryness. The dark brownish red residue was chromatographed over silica gel (60-200 mesh, deactivated with $\left.3 \mathrm{wt}, \% \mathrm{NH}_{4} \mathrm{OH}\right)$ using firstly hexane as eluant to elute unchanged bromide 4, and then ether-hexane (1:1) to elute $102 \mathrm{mg}$ (30\%) of photochrome 5. Recrystallization from cyclohexane yielded brownish-red crystals, mp $168-69^{\circ} \mathrm{C}$. [NMR assignments were made by COSY, NOESY, HMQC and HSQC 2D expts] ${ }^{1} \mathrm{H}$ NMR $\left(\mathrm{CDCl}_{3}, 500 \mathrm{MHz}\right) \delta 8.74-8.70(\mathrm{~m}, 4, \mathrm{H}-9,12), 8.29(\mathrm{~d}, J=0.9 \mathrm{~Hz}, 2, \mathrm{H}-1), 8.23(\mathrm{~d}, J$ $=0.9 \mathrm{~Hz}, 2, \mathrm{H}-8), 8.00(\mathrm{~d}, J=1.2 \mathrm{~Hz}, 2, \mathrm{H}-3), 7.64-7.60(\mathrm{~m}, 4 \mathrm{H}, \mathrm{H}-10,11), 7.31$ (s $\left.\mathrm{s}^{\mathrm{a}}, 2, \mathrm{H}-6\right)$, 
7.236 (note: $\mathrm{CHCl}_{3}$ is at 7.240) (d, $\left.J=0.7 \mathrm{~Hz}, 2, \mathrm{H}-5\right), 1.56\left(\mathrm{~s}, 18,2-\mathrm{C}\left(\mathrm{C}_{3}\right)_{3}\right), 1.49(\mathrm{~s}, 18,7-$

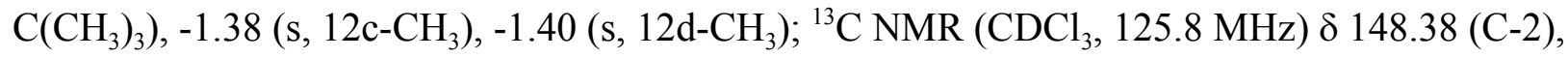
145.66 (C-7), 144.77 (C-3a), 137.95 (C-12e), 137.55 (C-12b), 135.22 (C-5a), 129.75 (C-12f), 129.44 (C-12a), 126.56 and 126.33 (C-10,11), 124.85 and 124.75 (C-9,12), 122.68 (C-5), 119.55 (C-6), 118.63 (C-3), 117.72 (C-8), 117.52 (C-1), 112.32 (C-4), 83.90 (C-1'), 79.93 (C-2' ), 37.11 (C-12c), $36.13\left(2-\underline{\mathrm{C}}\left(\mathrm{CH}_{3}\right)_{3}\right), 35.66\left(7-\underline{\mathrm{C}}\left(\mathrm{CH}_{3}\right)_{3}\right), 35.49(\mathrm{C}-12 \mathrm{~d}), 30.88\left(2-\mathrm{C}\left(\underline{\mathrm{C}} \mathrm{H}_{3}\right)_{3}\right), 30.76(7-$ $\left.\mathrm{C}\left(\underline{\mathrm{CH}}_{3}\right)_{3}\right), 18.25\left(12 \mathrm{c}, \mathrm{d}-\mathrm{CH}_{3}\right) ; \mathrm{UV}$ (cyclohexane) $\lambda_{\max } \mathrm{nm}\left(\varepsilon_{\max }\right) 282(19,300), 331(15,000), 415$ (23,500), $438(16,400), 525(6,830)$, tail to $700 \mathrm{~nm}$; IR (KBr) $\vee 2214 \mathrm{~cm}^{-1}$; MS FAB $m / z 834.5$ $\left(\mathrm{M}^{+}\right)$; HRMS: Calcd for $\mathrm{C}_{64} \mathrm{H}_{32}: 834.516$. Found : 834.518. Attempted elemental analysis gave a carbon, $0.5 \%$ low, not uncommon with high $\mathrm{C}$ compounds.

${ }^{1}$ Sheepwash, M. A.; Ward, T. R.; Wang, Y.; Bandyopadhyay, S.; Mitchell, R. H.; Bohne, C. Photochem. Photobiol. Sci. 2003, 2, 104-122.

${ }^{2}$ Sarkar, A.; Okada, S.; Nakanishi, H.; Matsuda, H. Helv. Chim. Acta 1999, 82, 138-141.

${ }^{\text {a }}$ Although H-6 appears as a singlet, COSY spectra indicate a small coupling to H-5 and H-8.

\section{Visible Opening to cyclophanediene form.}

The dihydropyrene form, C-C $5(5 \mathrm{mg})$ in $\mathrm{CDCl}_{3}(0.6 \mathrm{~mL})$ in a quartz $\mathrm{nmr}$ tube (Wilmad, 535PP-7QTZ), purged with argon and cooled by ice water was irradiated with a 500-W household tungsten-halogen lamp (Globe Electric, Montreal, Quebec, Canada, T-3, 8500 lumens) with an orange plastic filter (permits only light $\lambda>490 \mathrm{~nm}$ to pass) between the lamp and the sample, until the color of the solution was pale yellow. The ${ }^{1} \mathrm{H}$ NMR spectrum was run at intervals, and showed no high field protons around $\delta-1.5$ when complete, about 20 mins. 
The solution then contains essentially pure cyclophanediene form, O-O 5. ${ }^{1} \mathrm{H} \mathrm{NMR}(300 \mathrm{MHz}) \delta$ 7.65-7.59 (m, 4), 7.41-7.34 (m, 4), $7.12(\mathrm{~s}, 1), 7.11(\mathrm{~s}, 1), 6.93(\mathrm{~s}, 2), 6.90-6.84(\mathrm{~m}, 4), 6.78(2 \mathrm{~s}$, 2), $1.28(\mathrm{~s}, 18), 1.24$ (s, 18), $1.20(\mathrm{~s}, 6), 1.17$ (s, 6); ${ }^{13} \mathrm{C}$ NMR (75.5 MHz) d 151.45, 150.62, $143.96,143.85,142.37,140.69,140.23,139.91,138.91,138.40,135.99,135.29,129.61,128.98$, $128.92,128.53,124.47,123.26,123.00,109.96,86.91,80.99,34.51,34.34,32.16,32.05,31.53$, $31.48,29.92,19.37,18.69$. This solution contains two diastereomers, however the internal $\mathrm{CH}_{3}$ and the external $-\mathrm{C}\left(\mathrm{CH}_{3}\right)_{3}$ protons do not distinguish these. The spectra obtained at intermediate times showed mixtures of the $\mathrm{O}-\mathrm{O}$ and $\mathrm{C}-\mathrm{C}$ species to be present. The same spectra were observed when a red plastic filter (stops light $\lambda<590 \mathrm{~nm}$ ) was used. UV-vis spectra were obtained on $3 \times 10^{-5} \mathrm{M}$ solutions in cyclohexane - see text.

\section{UV Closing to the dihydropyrene form}

The above NMR sample was then irradiated with a low pressure $\mathrm{Hg}$ (Ar) pencil light (Oriel 6035) (254 nm) cooled with an electric fan, and the ${ }^{1} \mathrm{H}$ NMR spectrum was recorded at intervals. The peaks of the $\mathbf{O}-\mathbf{O}$ form were slowly replaced with those of the $\mathbf{C}-\mathbf{C}$ form. No signals that could definitely be ascribed to an intermediate $\mathbf{O}-\mathbf{C}$ form could be seen (even though it can be seen in UV-vis spectra, see text), but because two diastereomers are present, and because no large shift changes of either the closed or the open parts of $\mathbf{O}-\mathrm{C}$ are expected from $\mathbf{O}-\mathbf{O}$ or from C-C respectively, the increased broadness of the peaks due to the number of isomers, may prevent useful information from being obtained by NMR. We also attempted irradiation in $\mathrm{d}_{6}{ }^{-}$ benzene, but again no additional peaks could be seen. UV-vis spectra were obtained on $3 \times 10^{-5} \mathrm{M}$ solutions in cyclohexane - see text. 